\title{
STUDI PERBANDINGAN PERBAIKAN KUALITAS CITRA GESTUR TANGAN MENGGUNAKAN METODE HISTOGRAM EQUALIZATION DENGAN ADAPTIVE HISTOGRAM EQUALIZATION
}

\section{COMPARISON STUDY OF HAND GESTURES IMAGE QUALITY IMPROVEMENT USING HISTOGRAM EQUALIZATION METHOD USING ADAPTIVE HISTOGRAM EQUALIZATION}

\author{
Muhammad Abdul Aziz ${ }^{1)}$, Resty Wulanningrum ${ }^{2)}$, Daniel Swanjaya ${ }^{3)}$ \\ 1),2),3) Program Studi Teknik Informatika, Fakultas Teknik, Universitas Nusantara PGRI Kediri \\ Jl. Ahmad Dahlan No.76, Mojoroto, Kec. Mojoroto, Kota Kediri \\ Email : muhammadabdulaziz884@gmail.com ${ }^{1)}$,restyw@unpkdr.ac.id ${ }^{2}$, daniel@unpkediri.ac.id ${ }^{3}$ )
}

\begin{abstract}
Abstrak
Menciptakan lingkungan yang aman di lingkungan sekolah dapat dilakukan dengan memasang CCTV yang dilengkapi aplikasi yang mampu mendeteksi masalah lewat pola gerakan gestur tangan. Namun dalam proses pengenalan pola gestur tangan terkendala oleh pengambilan data citra capture gestur tangan dari CCTV yang kualitas kontras citra kurang merata. Tujuan dari penelitian ini adalah untuk membuat sebuah sistem yang dapat melakukan perbaikan kualitas citra hasil capture gestur tangan dari CCTV. Dalam melakukan penelitian ini akan menggunakan metode histogram equalization dan adaptive histogram equalization dan selanjutnya membandingkan hasil perbaikan kualitas citra diantara kedua metode yang digunakan. Data citra yang akan digunakan dalam penelitian ini yaitu citra gestur tangan melambai. Dari hasil uji coba yang sudah dilakukan didapatkan hasil bahwa penggunaan metode adaptive histogram equalization lebih baik dari pada metode histogram equalization yang mana dari segi tampilan visual histogram equalization menunjukan hasil yang lebih gelap dari pada metode adaptive histogram equalization. Sedangkan untuk hasil nilai rata-rata MSE paling rendah didapatkan oleh metode adaptive histogram equalization yaitu sebesar 102.368 untuk tabel 3 (citra pencahayaan terang) dan 120.162 untuk tabel 4 (citra pencahayaan redup), dan untuk metode histogram equalization mendapatkan nilai rata-rata MSE sebesar 214.473 dan 262.285 .
\end{abstract}

Kata kunci: Adaptive Histogram Equalization, Gestur Tangan, Histogram Equalization, Perbaikan.

\begin{abstract}
Creating a safe environment in the school environment can be done by installing CCTV equipped with applications that can detect problems through hand gesture movement patterns. However, the process of recognizing hand gesture patterns is constrained by the retrieval of hand gesture capture image data from CCTV which is still not clear, not sharp, and blurry. The purpose of this study is to create a system that can improve image quality as a result of capturing hand gestures from CCTV. In conducting this research, the histogram equalization and adaptive histogram equalization methods will be used, and then compare the results of image quality improvement between the two methods used. The image data that will be used in this study is the image of a waving hand gesture. From the results of the experiments that have been carried out, it is found that the use of the adaptive histogram equalization method is better than the histogram equalization method which in terms of visual appearance histogram equalization shows darker results than the adaptive histogram equalization method. Meanwhile, the lowest MSE average value was obtained by the adaptive histogram equalization method, which was 102,368 for table 3 (image of bright lighting) and 120,162 for table 4 (image of dim lighting), and for the histogram equalization method, the MSE average value was 214,473 and 262,285 .
\end{abstract}

Keywords : Adaptive Histogram Equalization, Hand Gesture, Histogram Equalization, Improve.

\section{PENDAHULUAN}

Sekolah merupakan sebuah lembaga pendidikan formal bagi para pelajar untuk menuntut ilmu [1]. Oleh karena itu penting bagi pihak sekolah untuk berupaya menciptakan lingkungan 
yang nyaman serta aman bagi semua orang baik bagi para siswa, guru, maupun staf pekerja lainnya. Untuk menciptakan lingkungan yang nyaman dapat dilakukan dengan memberikan fasilitas yang memadai sedangkan untuk menciptakan lingkungan yang aman dapat diwujudkan dengan memanfaatkan teknologi dari CCTV (Closed Circuit Television). Umumnya kamera CCTV (Closed Circuit Television) digunakan untuk keamanan, meniadakan resiko kehilangan, mengawasi dan merekam segala bentuk aktifitas dalam suatu area secara real-time [2]. Fungsi kamera CCTV adalah untuk memantau keadaan dalam suatu tempat, yang biasanya berkaitan dengan keamanan atau tindak kejahatan. [3] CCTV digunakan untuk merekam gambar bergerak (video) dengan menggunakan kamera di tempat dimana perangkat dipasang. Video yang direkam ditayangkan pada komputer untuk melihat seluruh aktivitas yang di rekam CCTV tersebut. Apabila hasil tangkapan layar diperbesar, maka gambar yang ditampilkan menjadi kabur [4].Penggunaan CCTV ini digunakan untuk melakukan pengawasan, pengontrolan serta menjaga keamanan di area-area penting sekolahan seperti di ruang kelas, lab komputer, ruang kantor guru, tempat parkir dan tempat lainya. Dalam melakukan pengawasan menggunakan CCTV ini agar lebih efisien dan efektif maka dibuatkan sebuah aplikasi yang mampu mendeteksi masalah lewat pola gerakan gestur tangan yang ada di CCTV. Namun dalam proses melakukan pengenalan pola gestur tangan ini terkendala oleh kualitas pengambilan data citra capture gestur tangan dari CCTV yang masih kurang jelas, kurang tajam, buram dan sebagainya. Oleh karena itu untuk meningkatkan hasil citra capture gestur tangan dari CCTV tersebut agar bisa dikenali oleh aplikasi maka dibutuhkan suatu perbaikan kualitas citra agar citra yang dihasilkan dapat dikenali dengan jelas.

Pada penelitian sebelumnya yang dilakukan oleh Apriska Ade Aristanti, Resty Wulanningrum pada tahun 2020 dengan judul Sistem Pertolongan Pertama Dengan Pola Tangan Menggunakan Machine Learning. Pada penelitian ini membahas mengenai sebuah sistem yang bisa mengenali pola gestur tangan yang ingin melakukan tindakan kejahatan pada suatu tempat yang diawasi dengan CCTV menggunakan machine learning [5].

Penelitian lain yang digunakan sebagai referensi yaitu penelitian yang dilakukan oleh I Wayan Angga Wijaya Kusuma, Afriliana Kusumadewi pada tahun 2020 dengan judul Penerapan Metode Contrast Stretching, Histogram Equalization dan Adaptive Histogram Equalization UUntuk Meningkatkan Kualitas Citra Medis MRI. Pada penelitian ini membahas mengenai bagaimana cara meningkatkan kualitas citra medis MRI Otak baik dalam kondisi normal ataupun dalam kondisi yang mengalami lesi (gangguan) dengan menggunakan metode Contrast Stretching, histogram equalization dan Adaptive Histogram Equalization. [6].

Permasalahan yang dapat dirumuskan pada penelitian ini adalah bagaimana membuat sebuah sistem atau aplikasi yang mampu meningkatkan kualitas citra hasil capture gestur tangan dari CCTV agar bisa dikenali aplikasi atau digunakan untuk tahap selanjutnya yaitu tahap pengenalan gestur tangan. Sedangkan tujuan dari penelitian ini adalah untuk membuat sebuah sistem yang dapat melakukan perbaikan kualitas citra hasil capture gestur tangan dari CCTV. Dalam melakukan penelitian ini akan menggunakan metode histogram equalization dan adaptive histogram equalization dan selanjutnya membandingkan hasil perbaikan kualitas diantara kedua metode yang digunakan.

\section{DASAR TEORI}

\section{1) Citra Digital}

Citra merupakan suatu representasi, kemiripan atau imitasi dari suatu obyek atau benda[7]. Pada saat yang sama, dari sudut pandang matematis, citra merupakan sebuah fungsi berkelanjutan dari intesitas cahaya dalam bidang dua dimensi [8]. Citra (image) atau istilah lain untuk gambar sebagai salah satu komponen multimedia yang memegang peranan sangat penting sebagai bentuk informasi visual [9]. Citra digital adalah sebuah larik (array) yang berisi bilangan nyata (real) dan kompleks yang diwakili oleh serangkaian bit tertentu. Suatu citra dapat didefinisikan sebagai fungsi $\mathrm{f}(\mathrm{x}, \mathrm{y})$ dengan ukuran $\mathrm{M}$ baris dan $\mathrm{N}$ kolom, dimana $\mathrm{x}$ dan $\mathrm{y}$ adalah koordinat spasial, dan amplitudo f pada titik koordinat (x,y) disebut intensitas atau tingkat keabuan dari citra pada titik tersebut [10]. 


\section{2) Perbaikan Citra}

Tujuan perbaikan citra (image enhancement) adalah untuk meningkatkan kualitas tampilan citra agar lebih mudah dikenali oleh mata manusia atau mengubah citra ke bentuk yang lebih baik, sehingga komputer atau aplikasi dapat memproses citra dengan lebih mudah [10]. Dalam memperbaiki kualitas citra dapat dilakukan dengan beberapa metode seperti metode histogram equalization dan adaptive histogram equalization dan sebagainya. Melihat beragamnya metode perbaikan kualitas citra, sebuah citra tentu mempunyai suatu bayangan, karakter latar belakang dan objek yang ada pada citra itu sendiri [11].

\section{3) Metode Histogram Equalization}

Metode histogram equalization (HE) merupakan sebuah proses memeratakan histogram citra dengan cara mengubah nilai keabuan suatu piksel menjadi nilai keabuan baru yang berbeda dari aslinya melalui suatu proses transformasi [8]. Tujuan dari histogram equalization adalah untuk mendistribusikan tingkat abu-abu dalam sebuah citra sehingga setiap tingkat abu-abu sama mungkin terjadi [12].

\section{4) Metode Adaptive Histogram Equalization}

Adaptive Histogram Equalization (AHE) adalah teknik pengolahan citra yang digunakan untuk memperbaiki kontras pada citra [13]. Metode adaptive histogram equalization (AHE) pada dasarnya sama dengan histogram equalization. Namun pada adaptive histogram equalization citra akan dipilah menjadi beberapa area (sub-image) dengan ukuran $\mathrm{n} \times \mathrm{n}$, kemudian pada setiap area yang dibagi akan dilakukan proses histogram equalization. Ukuran area (n) dapat bermacammacam dan setiap ukuran area akan memberikan hasil yang beragam. Selain itu setiap area dapat saling tumpang tindih beberapa piksel dengan area lainnya [10].

\section{METODOLOGI PENELITIAN}

Metodologi penelitian merupakan suatu tahapan-tahapan yang dikerjakan dalam sebuah penelitian yang berfungsi untuk mengumpulkan data atau informasi. Metodologi yang digunakan untuk mengembangkan penelitian ini yaitu metode waterfall yang mana penelitian akan dilakukan secara bertahap, berurutan dan sistematis. Berikut ini metodologi penelitian yang akan digunakan dapat dilihat pada gambar 1.

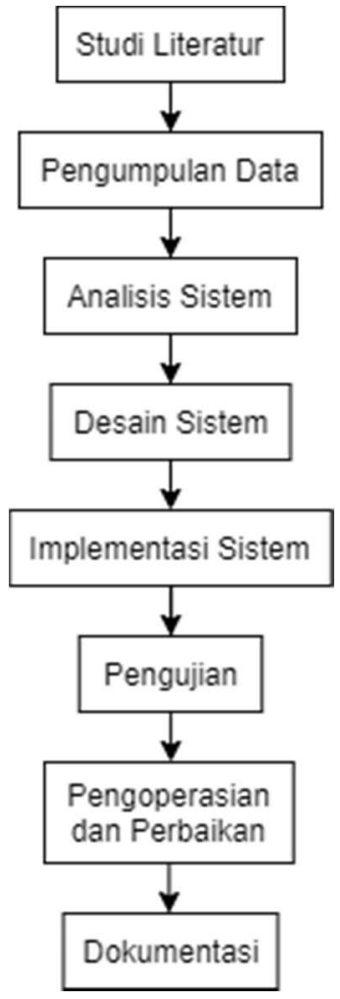

Gambar 1. Metodologi Penelitian 
Dari gambar 1, yang secara garis besar dapat dijelaskan sebagai berikut ini:

[1] Studi Literatur

Pada langkah ini dilakukan pencarian mengenai karya tulis ilmiah, jurnal, e-book, buku, artikel-artikel di internet yang akan digunakan sebagai referensi.

[2] Pengumpulan Data

Data yang dikumpulkan pada penelitian ini berupa foto yang isinya gerakan gestur tangan melambai. Dalam pengambilan data sampel citra ini menggunakan bantuan dari kamera handphone.

[3] Analisis Sistem

Pada tahapan ini dilakukan untuk membuat sebuah rancangan alur sistem serta menentukan algoritma yang akan digunakan dalam program.

[4] Desain Sistem

Desain yang akan dibuat pada proses ini berupa desain antar muka program yang akan digunakan oleh pengguna aplikasi. Kemudian untuk alur program akan dibuat menggunakan diagram flowchart.

[5] Implementasi Sistem

Proses utama dalam implementasi sistem ini adalah proses pembuatan sebuah program menggunakan bahasa pemrograman python.

[6] Pengujian

Bertujuan untuk mengecek apakah program yang sudah dibuat bisa berjalan sesuai dengan rancangannya dan untuk mengecek apakah dalam program tersebut masih ada kesalahan atau tidak.

[7] Pengoperasian dan Perbaikan

Pada tahapan ini program yang sudah jadi akan dicoba dijalankan dan apabila ada error akan diperbaiki.

[8] Dokumentasi

Tahap dokumentasi ini merupakan tahap pembuatan laporan penelitian dan kesimpulan.

\section{PENGUJIAN DAN PEMBAHASAN}

\subsection{Flowchart perbaikan kualitas citra}

Pada gambar 2 menunjukan sebuah flowchart metode histogram equalization dan adaptive histogram equalization. Flowchart ini merupakan sebuah alur atau langkah-langkah garis besar yang berfungsi untuk melakukan perbaikan kualitas citra gestur tangan. 


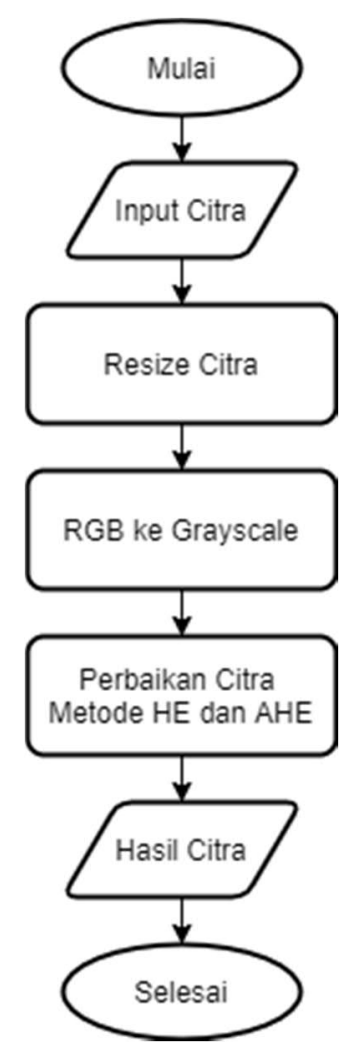

Gambar 2. Flowchart Metode Histogram Equalization dan Adaptive Histogram Equalization

Berikut ini uraian penjelasan dari langkah-langkah yang ada di gambar 2:

1. Proses mulai.

2. Memasukan citra gestur tangan.

3. Selanjutnya citra akan dilakukan resize dengan ukuran 185 × 247 piksel, resize ini digunakan untuk mempermudah dalam proses perhitungan disetiap blok citra yang akan diolah.

4. Proses mengubah citra yang diinputkan dari citra RGB dikonversi kedalam format citra grayscale. Ketika dalam proses konversi, citra dengan derajat keabuan telah didapatkan [14]

5. Proses dalam melakukan perbaikan kualitas citra gestur tangan menggunakan metode histogram equalization dan adaptive histogram equalization.

Histogram menyatukan peluang piksel dengan derajat keabuan tertentu, maka rumus menghitung histogram ditulis sebagai peluang[15]:

$$
\left.P_{r}\left(r_{k}\right)=\frac{n_{k}}{n} \ldots \ldots \ldots \ldots \ldots \ldots 1\right)
$$

Yang dalam hal ini,

$$
\left.r_{k}=\frac{k}{L-1} \ldots, 0 \leq r_{k} \geq 1 \ldots . .2\right)
$$

Dengan mengubah derajat keabuan suatu piksel (r) menjadi derajat keabuan yang baru (s) dengan suatu fungsi transformasi $\mathrm{T}$ yang dalam hal ini $\mathrm{s}=\mathrm{T}(\mathrm{r})$, maka untuk perataan histogram digunakan rumus:

$$
s_{k}=T\left(r_{k}\right)=\sum_{j=0}^{k} \frac{n_{j}}{n}=\sum_{j=0}^{k} P_{r}\left(r_{j}\right)
$$

6. Menampilkan citra hasil perbaikan kualitas.

7. Proses selesai.

\subsection{Desain Interface Aplikasi} pada gambar 3 .

Untuk desain interface aplikasi yang akan digunakan dalam penelitian ini dapat dilihat 


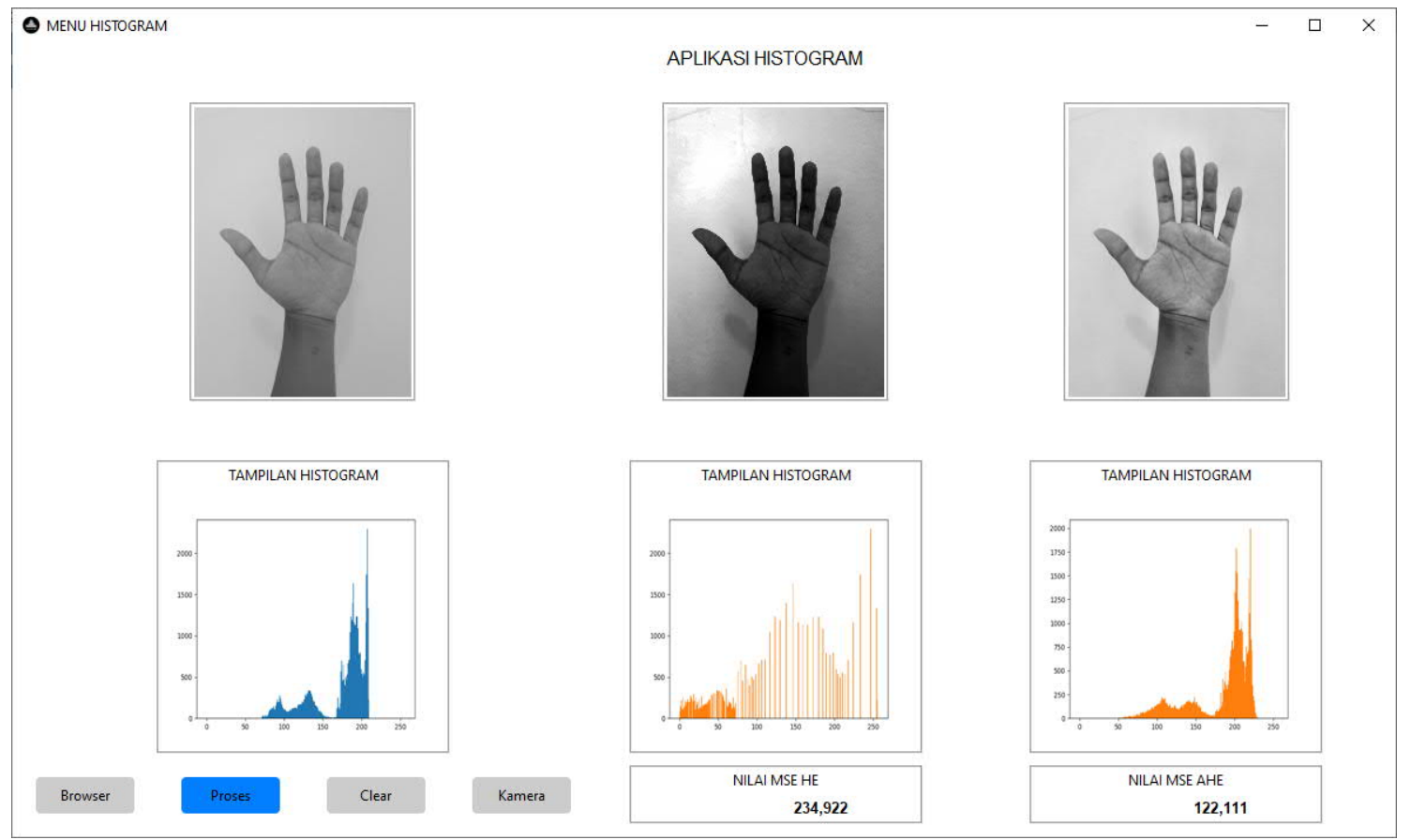

Gambar 3. Desain Interface Aplikasi

Dari gambar 3 dapat dijelaskan beberapa fitur yang akan digunakan yaitu fitur browser, digunakan untuk memasukkan citra gestur tangan. Selanjutnya fitur proses, digunakan untuk memulai proses perbaikan kualitas citra gestur tangan berdasarkan kedua metode yang digunakan. Fitur clear, digunakan untuk menghapus atau mereset semua tampilan yang ada di aplikasi. Terakhir fitur exit, digunakan untuk keluar dari aplikasi. Selain beberapa fitur utama yang sudah dijelaskan, ada beberapa fitur lainnya yang berguna untuk menampilkan citra asli, citra hasil perbaikan, histogram dari citra asli maupun citra hasil perbaikan dan untuk menampilkan nilai MSE (Mean Square Error) citra hasil perbaikan yang mana fitur ini yang akan digunakan untuk membedakan kualitas perbaikan citra kedua metode yang digunakan atau diuji dalam penelitian ini.

\subsection{Pengujian Perbaikan Citra}

Pada tahapan ini, citra yang akan digunakan dalam pengujian yaitu citra yang berukuran 185 x 247 piksel dan dalam format citra grayscale 8 bit. Sedangkan untuk data citra gestur tangan yang akan digunakan ialah citra gestur tangan yang sedang melambai. Untuk membandingkan dan menganalisa metode yang digunakan dalam penelitian ini akan menggunakan data sampel sebanyak enam citra gestur tangan melambai, selanjutnya dari keenam data citra tersebut akan dibagi menjadi 2 tabel yaitu tabel yang berisi data citra dengan kondisi pencahayaan terang dan tabel yang berisi data citra dengan kondisi pencahayaan redup. Selanjunnya data citra akan diolah atau diproses untuk dilakukan perbaikan kualitas citra menggunakan metode histogram equalization dan adaptive histogram equalization pada aplikasi yang sudah dibuat. Perbandingan antara kedua metode yang digunakan dalam perbaikan kualitas citra gestur tangan dapat dilihat pada tabel 1 dan tabel 2 . 
Tabel 1. Hasil Pengujian Citra Gestur Tangan Dengan Kondisi Pecahayaan Terang

\begin{tabular}{|l|c|c|c|}
\hline Nama & Citra Asli & $\begin{array}{c}\text { Citra Metode } \\
\text { Histogram } \\
\text { Equalization }\end{array}$ & $\begin{array}{c}\text { Citra Metode Adaptive } \\
\text { Histogram } \\
\text { Equalization }\end{array}$ \\
\hline Citra_tangan1 & & & \\
\hline
\end{tabular}


Tabel 2. Hasil Pengujian Citra Gestur Tangan Dengan Kondisi Pecahayaan Redup

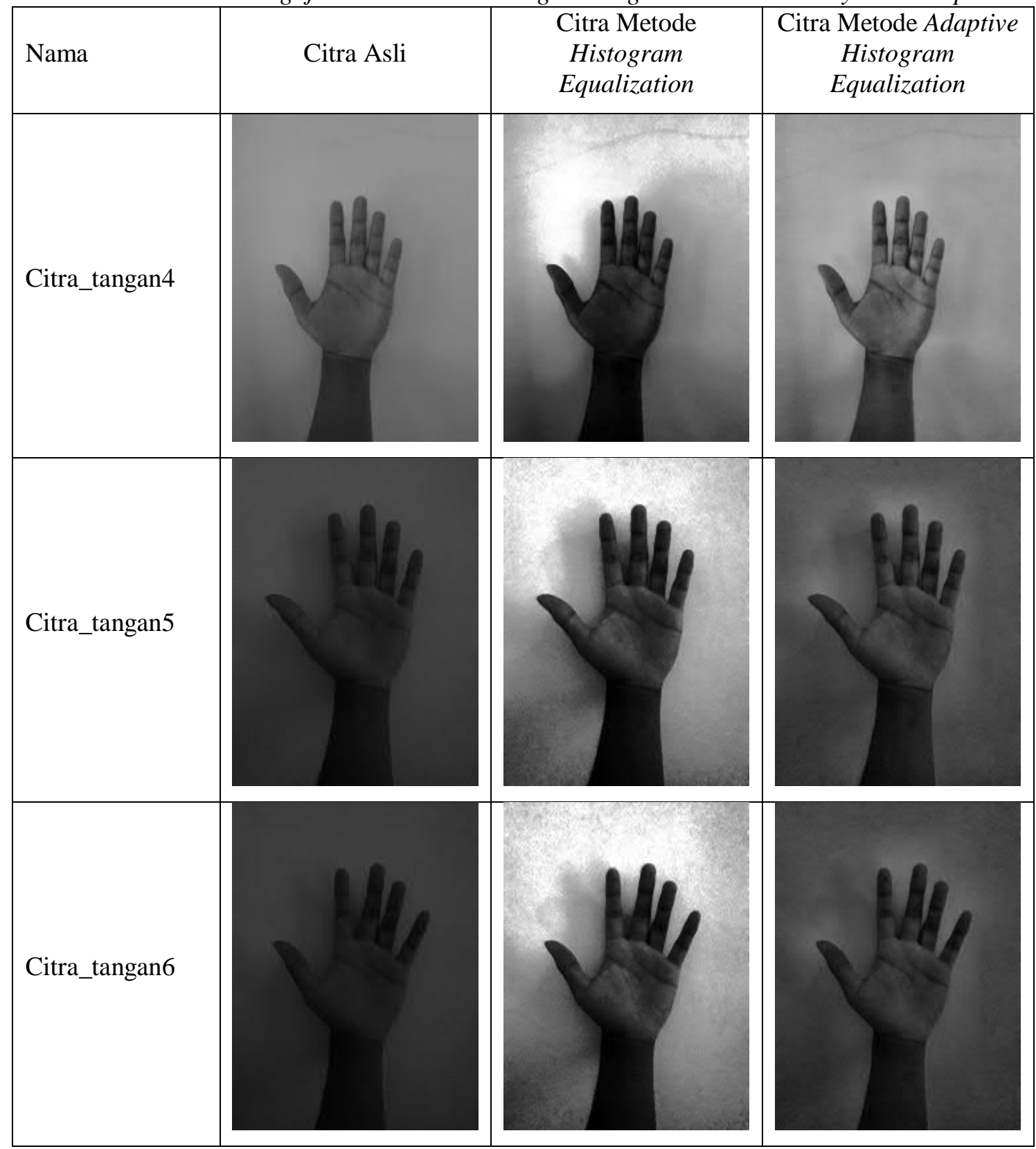

Dari hasil pengujian perbaikan kualitas data citra menggunakan metode histogram equalization dan adaptive histogram equalization pada tabel 1 dan tabel 2 dapat dilihat secara visual bahwa hasil perbaikan kualitas citra yang menggunakan metode histogram equalization didapatkan hasil citra yang lebih gelap daripada metode adaptive histogram equalization.

\subsection{Pengukuran Kualitas Citra}

Untuk mengetahui perbedaan kualitas perbaikan citra gestur tangan antara metode histogram equalization dengan adaptive histogram equalization dapat didasarkan pada perbedaan nilai error piksel dari citra asli dengan citra hasil perbaikan. Selanjutnya untuk menghitung nilai error piksel dari citra asli dengan citra hasil perbaikan dapat menggunakan perhitungan MSE (Mean Square Error). Berikut persamaan (1) untuk mencari nilai MSE:

$$
\mathrm{MSE}=\frac{1}{M . N} \sum_{x=0}^{M-1} \sum_{Y=0}^{N-1}[h(x, y)-g(x, y)]^{2}
$$

Dimana $\mathrm{h}(\mathrm{x}, \mathrm{y})$ merupakan citra hasil perbaikan, sedangkan $\mathrm{g}(\mathrm{x}, \mathrm{y})$ merupakan citra asli, kemudian $\mathrm{M}$ dan $\mathrm{N}$ merupakan ukuran panjang dan lebar sebuah citra. Citra perbaikan dengan 
nilai MSE yang bernilai kecil (mendekati 0) mempunyai kualitas citra yang lebih baik daripada citra perbaikan yang bernilai besar [16]. Berikut ini tabel 3 dan tabel 4 yang menunjukan hasil perhitungan nilai MSE untuk keenam sampel citra gestur tangan yang sudah dilakukan perbaikan dengan metode histogram equalization dan adaptive histogram equalization.

Tabel 3. Hasil Perhitungan Nilai MSE Citra Dengan Kondisi Pecahayaan Terang

\begin{tabular}{|l|l|l|}
\hline \multirow{2}{*}{ Nama } & \multicolumn{2}{c|}{ Nilai MSE } \\
\cline { 2 - 3 } & \multicolumn{1}{|c|}{$\begin{array}{c}\text { Metode Histogram } \\
\text { Equalization }\end{array}$} & $\begin{array}{c}\text { Metode Adaptive Histogram } \\
\text { Equalization }\end{array}$ \\
\hline Citra_tangan1 & 141.818 & 48.728 \\
\hline Citra_tangan2 & 234.922 & 122.111 \\
\hline Citra_tangan3 & 266.680 & 136.265 \\
\hline Rata-rata & 214.473 & 102.368 \\
\hline
\end{tabular}

Tabel 4. Hasil Perhitungan Nilai MSE Citra Dengan Kondisi Pecahayaan Redup

\begin{tabular}{|c|c|c|}
\hline \multirow{2}{*}{ Nama } & \multicolumn{2}{|c|}{ Nilai MSE } \\
\cline { 2 - 3 } & $\begin{array}{c}\text { Metode Histogram } \\
\text { Equalization }\end{array}$ & $\begin{array}{c}\text { Metode Adaptive Histogram } \\
\text { Equalization }\end{array}$ \\
\hline Citra_tangan4 & 203.367 & 127.224 \\
\hline Citra_tangan5 & 258.076 & 103.425 \\
\hline Citra_tangan6 & 325.413 & 129.837 \\
\hline Rata-rata & 262.285 & 120.162 \\
\hline
\end{tabular}

\section{KESIMPULAN}

Kesimpulan yang bisa didapatkan dari pembuatan sistem perbaikan kualitas citra gestur tangan menggunakan metode histogram equalization dan adaptive histogram equalization yaitu hasil visual perbaikan kualitas citra gestur tangan menggunakan metode histogram equalization menunjukan hasil citra yang lebih gelap daripada yang menggunakan metode adaptive histogram equalization. Sedangkan berdasarkan nilai MSE metode adaptive histogram equalization mempunyai nilai rata-rata yang lebih rendah yaitu 102.368 untuk tabel 3 (citra pencahayaan terang) dan 120.162 untuk tabel 4 (citra pencahayaan redup), sedangkan metode histogram equalization mempunyai nilai rata-rata lebih besar yaitu 214.473 untuk tabel 3 (citra pencahayaan terang) dan 262.285 untuk tabel 4 (citra pencahayaan redup). Dari penelitian yang sudah dilakukan ini dapat disimpulkan bahwa menggunakan metode adaptive histogram equalization menampilkan hasil yang lebih baik daripada menggunakan metode histogram equalization dikarena semakin kecil nilai MSE yang dihasilkan berarti semakin lebih baik kualitas citranya.

Diharapkan penelitian ini dapat dilanjutkan ketahap selanjutnya yaitu pengenalan gestur tangan sehingga dalam melakukan proses pengenalan pola gestur tangan nantinya bisa didapatkan hasil yang maksimal saat menggunakan metode adaptive histogram equalization untuk perbaikan kualitas citra gestur tangannya.

\section{Daftar Pustaka}

[1] Alpian, Y., Anggraeni, S. W., Wiharti, U., \& Soleha, N. M. (2019). Pentingnya pendidikan bagi manusia. Jurnal Buana Pengabdian, 1(1), 66-72.

[2] Nofrida, R. A., Hafidudin, H., \& Hartaman, A. (2017). Pengukuran Dan Evaluasi Qos Untuk Meningkatkan Kualitas Layanan Trafik Kamera Cctv (studi Kasus Gedung Selaru). eProceedings of Applied Science, 3(3).

169| N ERO 
[3] Aripin, S., \& Hasibuan, N. A. (2019, September). Penerapan Metode Interpolasi Linier dan Metode Adaptive Median Filter untuk Perbaikan Kualitas Citra pada Hasil CCTV. In Prosiding Seminar Nasional Riset Information Science (SENARIS) (Vol. 1, pp. 854-863).

[4] Khikmah, N. L., \& Wulaningrum, R. (2021, August). Perbaikan Citra Gambar Tangan Menggunakan Particle Swarm Optimization. In Prosiding SEMNAS INOTEK (Seminar Nasional Inovasi Teknologi) (Vol. 5, No. 2, pp. 093-099).

[5] Aristanti, A. A., \& Wulanningrum, R. (2020, December). Sistem Pertolongan Pertama dengan Pola Tangan Menggunakan Machine Learning. In Prosiding SEMNAS INOTEK (Seminar Nasional Inovasi Teknologi) (Vol. 4, No. 1, pp. 196-200).

[6] Kusuma, I. W. A. W., \& Kusumadewi, A. (2020). Penerapan Metode Contrast Stretching, Histogram Equalization Dan Adaptive Histogram Equalization Untuk Meningkatkan Kualitas Citra Medis MRI. Simetris: Jurnal Teknik Mesin, Elektro dan Ilmu Komputer, 11(1), 1-10.

[7] Purba, B. (2017). Aplikasi perbaikan kualitas citra hasil penginderaan jauh (remote sensing) dengan metode contrast stretching. Jurnal TIMES, 6(2), 26-36.

[8] Munir, R. (2004). Pengolahan citra digital dengan pendekatan algoritmik.

[9] Mau, S. D. B. (2016). Pengaruh Histogram Equalization Untuk Perbaikan Kualitas Citra Digital. Simetris: Jurnal Teknik Mesin, Elektro dan Ilmu Komputer, 7(1), 177-182.

[10] Putra, D. (2010). Pengolahan citra digital. Penerbit Andi.

[11] Nurraharjo, E. (2011). Implementasi Morphology concept and technique dalam pengolahan citra digital untuk menentukan batas obyek dan latar belakang citra. Dinamik, 16(2).

[12] Riadi, A. A., Chamid, A. A., \& Sokhibi, A. (2017). Analisis komparasi metode perbaikan kontras berbasis histogram equalization pada citra medis. Simetris: Jurnal Teknik Mesin, Elektro dan Ilmu Komputer, 8(1), 383-388.

[13] Gonzalez, Woods, Digital Image Processing 2nd Edition, Prentice Hall, 2002.

[14] Mufarroha, F. A., Sirajuddin, I. A., \& Kusumaningsih, A. (2018). Deteksi Manusia Menggunakan Metode Histogram Of Oriented Gradient Dan Euclidean Distance. Network Engineering Research Operation, 3(3).

[15] Mau, S. D. B. (2016). Pengaruh Histogram Equalization Untuk Perbaikan Kualitas Citra Digital. Simetris: Jurnal Teknik Mesin, Elektro dan Ilmu Komputer, 7(1), 177-182.

[16] Acharya, T., \& Ray, A. K. (2005). Image processing: principles and applications. John Wiley \& Sons. 